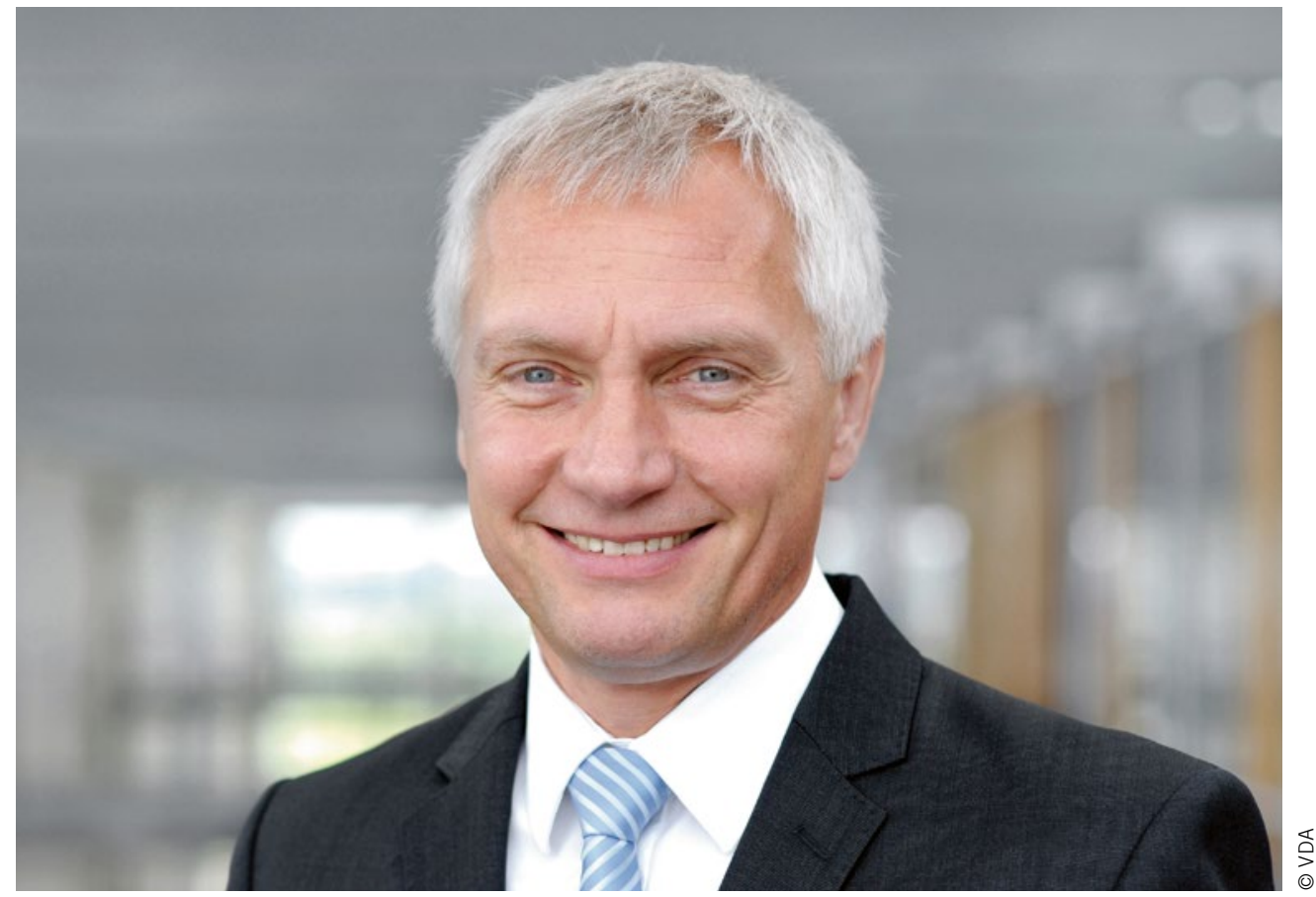

Dr.-Ing. Joachim Damasky Geschäftsführer Technik und Umwelt des Verbands der Automobilindustrie (VDA) und Geschäftsführer der Forschungsvereinigung Automobiltechnik (FAT), ATZ-Beirat

\title{
Mehr Sicherheit, Effizienz und Komfort
}

Das vernetzte und automatisierte Fahren ist heute - neben der Antriebstechnik - der wichtigste Entwicklungsschwerpunkt. Damit wird das Ziel verfolgt, individuelle Mobilität noch effizienter, komfortabler und vor allem sicherer zu machen. Denn menschliches Fehlverhalten ist für mehr als $90 \%$ der Unfälle im Straßenverkehr verantwortlich. Die Vernetzung und das automatisierte Fahren werden diese Unfallursachen deutlich zurückdrängen. Ein Fahrzeug, das in der Lage ist, eigenständig Fahrfunktionen zu übernehmen, kann auch beurteilen, ob der Fahrer sich in einem sicheren Fahrzustand bewegt. Somit kann er jederzeit über ein nahendes Stauende, bewegte Objekte oder auch nicht angepasste Geschwindigkeit informiert werden. Zudem verbessern elektronische Systeme den Verkehrsfluss. Das spart Sprit und Emissionen.

Derzeit befinden wir uns in der Phase, in der aus Fahrerassistenzsystemen teilautomatisierte Fahrfunktionen entstehen, die den Fahrer in schwierigen oder unterfordernden Situationen unterstützen - beim Stop-and-Go, im Stau, bei monotonen Autobahnfahrten mit Geschwindigkeitsbegrenzung, beim Abstandhalten zum Vordermann, beim plötzlichen Abbremsen, beim Einparken in unübersichtlichen Parkhäusern, beim Spurwechsel oder Abbiegen. Die Assistenztechnik setzt also genau dort an, wo ein erheblicher Teil der Unfallursachen zu suchen ist.

Aber nicht nur die Pkw-Hersteller engagieren sich hier. Auch die Nutzfahrzeugindustrie gehört zu den Vorreitern, wenn es um mehr Sicherheit im Verkehr geht. Das automatisierte Schalt- getriebe oder die elektronisch gesteuerten Brems- und Notbremssysteme sind nur einige der Technologien, die zuerst im Nutzfahrzeug zum Einsatz kamen, bevor sie zur optionalen Pkw-Ausstattung wurden.

Nutzfahrzeuge sind aufgrund ihrer hohen Fahrleistung (pro Jahr deutlich über $100.000 \mathrm{~km}$ ) prädestiniert für das automatisierte Fahren. Und noch mehr als beim Pkw ist für den Erfolg des Nutzfahrzeugs die Effizienz entscheidend: Wieviel Kraftstoff wird pro transportierter Tonne auf $100 \mathrm{~km}$ benötigt? Aufgrund der hohen Laufleistung wirken sich bereits kleine Beträge in Summe erheblich aus.

Erst vor Kurzem haben Lastwagenhersteller bei der European Truck Challenge das Platooning - eine voll vernetzte LkwKolonne, bei der der erste Lkw das Tempo angibt und die anderen im Windschatten folgen - im grenzüberschreitenden Großversuch getestet. Wie nah die Nutzfahrzeugindustrie der Vision vom automatisiert fahrenden Truck bereits gekommen ist, zeigte die 66. IAA Nutzfahrzeuge in Hannover. Mit dem neuen Format „New World Mobility Logistics“ wurden in diesem Jahr auf der IAA zahlreiche Innovationen gezeigt, durch die Güterverkehr und Mobilität effizienter, grüner, smarter und noch sicherer werden.

Es ist ganz klar: Um die Sicherheit auf den Straßen zu erhöhen, die Verkehrsströme effizienter zu leiten und die Emissionen weiter zu senken, brauchen wir die neue digitale Technik. Sie bietet zudem die Chance, Transportaufgaben noch effizienter zu lösen. 